\title{
Could Down-Regulation of Muscle-Specific MircoRNAs Provoke Functional Dyspepsia in Helicobacter pylorïInfected Stomach? (Gastroenterology 2011;140:189-198)
}

Byung Hwan Lee ${ }^{1}$ and Nayoung $\mathrm{Kim}^{1,2 *}$

${ }^{1}$ Department of Internal Medicine, Seoul National University Bundang Hospital, Seongnam, Gyeonggi-do, Korea, ${ }^{2}$ Department of Internal Medicine and Liver Research Institute, Seoul National University College of Medicine, Seoul, Korea

\section{Summary}

Pathogenesis of functional dyspepsia has not been well-established and it's treatment is frequently not satisfactory. Recently Saito et al ${ }^{1}$ suggested that dysfunctional gastric emptying could be induced by down-regulation of muscle-specific mircoRNAs (miRNAs) in Helicobacter pylori (H. pylori)-infected mice (C57BL/6) for 40 weeks. They demonstrated that miRNAs, which are associated with myogenic regulation such as $m i R-1$ and $m i R-133$, were significantly down-regulated, and histone deacetylase 4 and serum response factor, which are reported to be target genes of miRNAs, were increased in the muscular layers of stomach in the $H$. pylori-infected mice. Muscular hypertrophy was observed as a result of this effect on posttranscriptional level induced by $H$. pylori infection, and gastric emptying was accelerated in $H$. pylori-infected mice. In addition, down-regulation of $m i R-1, m i R-133 \mathrm{a}$ and $m i R-133 b$ and increased cell proliferation were observed in $\mathrm{C} 2 \mathrm{C} 12$ mouse myoblast cells after coculture with $H$. pylori. ${ }^{1}$ Furthermore, $m i R-1$ and $m i R-133$ were also sig- nificantly decreased in patients with $H$. pylori infection. ${ }^{1}$

The authors concluded that chronic infection with $H$. pylori down-regulated the expression of muscle-specific miRNAs and up-regulated expression of histone deacetylase 4 and serum response factor. These changes might cause hyperplasia in the muscular layer of the stomach and dysfunction in gastric emptying.

\section{Comment}

H. pylori has been regarded as one of the major causes in functional dyspepsia and this view has been supported by several epidemiologic studies. ${ }^{2,3}$ However, the pathogenesis of functional dyspepsia caused by $H$. pylori was not clearly illuminated so far. Numerous studies have been conducted for evaluation of the association between chronic $H$. pylori infection and gastric motility or perception. In regard to gastric dysmotility, it's type has not been established well. Heterogeneous type of abnormal gastric motility was suggested in the pathognomic mechanism of functional dyspepsia such as delayed gastric emptying, accelerated gastric emptying, antral hypomotility with altered intestinal mo-

Received: March 1, 2011 Revised: None Accepted: March 6, 2011

(c) This is an Open Access article distributed under the terms of the Creative Commons Attribution Non-Commercial License (http://creativecommons. org/licenses/by-nc/3.0) which permits unrestricted non-commercial use, distribution, and reproduction in any medium, provided the original work is properly cited.

*Correspondence: Nayoung Kim, MD, PhD Department of Internal Medicine, Seoul National University Bundang Hospital, 300 Gumi-dong, Bundang-gu, Seongnam, Gyeonggi-do 463-707, Korea

Financial support: None.

Tel: +82-31-787-7008, Fax: +82-31-787-4051, E-mail: nayoungkim49@empal.com

Conflicts of interest: None. 
tility, and dysfunctional gastric accommodation. ${ }^{4,5}$ Actually, delayed gastric emptying was associated with functional dyspepsia in various studies. However, gastric emptying was not influenced by chronic $H$. pylori infection. ${ }^{6}$ In addition, no solid data has been introduced until now regarding the association of dyspeptic symptoms with dysfunctional gastric emptying. ${ }^{4,5}$

MicroRNAs are small non-coding RNAs that regulate gene expression at the post-transcriptional level via translational inhibition or mRNA degradation. ${ }^{7}$ This post-transcriptional role has been suggested to influence cellular development and maturation. ${ }^{7}$ Various researches suggested that miRNAs had inhibitory effect on translation, and dysregulation of miRNAs was considered as the pathogenesis in various disorders or carcinogensis. ${ }^{8,9}$ Zhang et $\mathrm{al}^{9}$ recently demonstrated that $m i R-21$ was over-expressed in specimens of gastric cancer and $H$. pylori-infected stomach, and suggested the relationship between miRNAs and gastric carcinogenesis. The $m i R-1$ and $m i R-133$ used in this study were muscle specific miRNAs, which are essential for normal myoblast differentiation and proliferation. ${ }^{7,8}$ Also, these miRNAs have been implicated in the pathogenesis and treatment of skeletal and cardiac muscular disorders. ${ }^{8}$ In this study, Saito et $\mathrm{al}^{1}$ firstly showed the role of $m i R-1$ and $m i R-133$ in gastric muscular layer and dysfunctional gastric emptying in chronic $H$. pylori-infected mice.

However, the critical problem of this study is a mismatch with human clinical studies as the authors also mentioned. In most of human studies for functional dyspepsia, $H$. pylori did not show influence on gastric emptying. ${ }^{4-6}$ That is, $H$. pylori was not associated with delayed gastric emptying. Instead functional dyspepsia was associated with accelerated gastric emptying or dysfunctional gastric accommodation. ${ }^{10,11}$ Furthermore, accelerated gastric emptying was observed in the stomach with chronic $H$. $p y$ lori infection especially in pediatric study. ${ }^{12}$ Therefore, further human studies are necessary to validate the association between aberrant expression of muscle-specific miRNAs and the gastric motility disorder associated with chronic $H$. pylori infection. In spite of this limitation, this article has provided a valuable insight into the molecular pathogenesis of gastric motility disorders, including functional dyspepsia.

\section{References}

1. Saito Y, Suzuki H, Tsugawa H, et al. Dysfunctional gastric emptying with down-regulation of muscle-specific microRNAs in Helicobacter pylori-infected mice. Gastroenterology 2011;140:189-198.

2. Moayyedi P, Soo S, Deeks J, et al. Eradication of Helicobacter pylori for non-ulcer dyspepsia. Cochrane Database Syst Rev 2006;2:CD 002096.

3. Ford AC, Qume M, Moayyedi P, et al. Helicobacter pylori "test and treat" or endoscopy for managing dyspepsia: an individual patient data meta-analysis. Gastroenterology 2005;128:1838-1844.

4. Mimidis K, Tack J. Pathogenesis of dyspepsia. Dig Dis 2008;26: 194-202.

5. Choung RS, Talley NJ. Novel mechanisms in functional dyspepsia. World J Gastroenterol 2006;12:673-677.

6. Koskenpato J, Korppi-Tommola T, Kairemo K, Färkkilä M. Longterm follow-up study of gastric emptying and Helicobacter pylori eradication among patients with functional dyspepsia. Dig Dis Sci 2000;45:1763-1768.

7. Wang H, Sun H, Guttridge DC. microRNAs: novel components in a muscle gene regulatory network. Cell Cycle 2009;8:1833-1837.

8. Townley-Tilson WH, Callis TE, Wang D. MicroRNAs 1, 133, and 206: critical factors of skeletal and cardiac muscle development, function, and disease. Int J Biochem Cell Biol 2010;42:1252-1255.

9. Zhang Z, Li Z, Gao C, et al. miR-21 plays a pivotal role in gastric cancer pathogenesis and progression. Lab Invest 2008;88:13581366.

10. Delgado-Aros S, Camilleri M, Cremonini F, Ferber I, Stephens D, Burton DD. Contributions of gastric volumes and gastric emptying to meal size and postmeal symptoms in functional dyspepsia. Gastroenterology 2004;127:1685-1694.

11. Bredenoord AJ, Chial HJ, Camilleri M, Mullan BP, Murray JA. Gastric accommodation and emptying in evaluation of patients with upper gastrointestinal symptoms. Clin Gastroenterol Hepatol 2003; 1:264-272.

12. Sýkora J, Malán A, Záhlava J, et al. Gastric emptying of solids in children with $H$. pylori-positive and $H$. pylori-negative non-ulcer dyspepsia. J Pediatr Gastroenterol Nutr 2004;39:246-252. 